\title{
OXYPETALUM (APOCYNACEAE) EN LA ARGENTINA: UNA NUEVA ESPECIE, NUEVOS SINÓNIMOS Y UNA CLAVE DE IDENTIFICACIÓN
}

\author{
Oxypetalum (Apocynaceae) in Argentina: a new species, new synonyms and an identification key
}

\author{
HÉCTOR A. KELLER
}

\begin{abstract}
Resumen: Oxypetalum venustum H. A. Keller (Apocynaceae: Asclepiadoideae: Asclepiadae: Oxypetalinae), una especie similar a $O$. fontellae S. A. Cáceres, se describe e ilustra sobre la base de un ejemplar hallado en la provincia de Corrientes. Además, se proponen dos nuevos sinónimos y se presenta una clave para identificar las especies hasta ahora documentadas para la Argentina.
\end{abstract}

\begin{abstract}
Palabras clave: Flora Argentina, Oxypetalum karstenianum, O. molle, O. oblanceolatum, O. sylvestre, O. venustum.

Summary: Oxypetalum venustum H. A. Keller (Apocynaceae: Asclepiadoideae: Asclepiadae: Oxypetalinae) is described and illustrated based on a specimen found in Corrientes Province. Moreover, two new synonyms are proposed, and an identification key to the species currently documented for the Argentinian flora is provided.
\end{abstract}

Key words: Argentinian flora, Oxypetalum karstenianum, O. molle, O. oblanceolatum, $O$. sylvestre, O. venustum.

\section{Introducción}

El último tratamiento integral para dar cuenta del género Oxypetalum R. Br. en la Argentina fue desarrollado por Meyer (1943) quien en aquel entonces documentaba para el país la presencia de 28 especies. La cifra fue creciendo con la posterior publicación de protólogos de nuevas especies (Cáceres Moral, 1993; Farinaccio et Keller, 2014; Keller, 2015; Martín et al., 2017), nuevos registros (Cáceres Moral, 1989; Farinaccio et Keller, 2014; Keller et Cáceres Moral, 2018), nuevas combinaciones (Liede et Meve, 2015; Rapini et al., 2011; Keller et al., inéd.) y catálogos (Ezcurra, 1999; Ezcurra et al., 2008). Toda esta producción ulterior, sumada a la omisión de una especie en las listas nacionales, O. guaraniticum Malme (Malme) publicada como Calostigma guaraniticum
Malme (1921), permite elevar esta cifra a un total de 49 taxones incluidos en 47 especies.

La reciente exploración de fragmentos de pastizales sobre suelo arenoso a los costados de la ruta nacional 118, Corrientes, Argentina, permitió hallar un ejemplar con una combinación de caracteres que no se ajustan a las especies del género hasta el presente descriptas, por lo que dicha novedad es publicada en la presente contribución bajo el nombre Oxypetalum venustum $\mathrm{H}$. A. Keller. Por su parte, el estudio de material de herbario, descripciones e ilustraciones de $O$. karstenianum Goyder \& Rapini y $O$. sylvestre (Hook. \& Arn.) Goyder \& Rapini permitió inferir que son taxones conespecíficos, ocurriendo lo mismo con $O$. molle Hook. \& Arn. y O. oblanceolatum Farinaccio \& Mello-Silva, con lo cual se proponen dos nuevos sinónimos.

${ }^{1}$ Instituto de Botánica del Nordeste-CONICET, Casilla de Correo 209, 3400-Corrientes, Argentina. E-mail: ibone@ agr.unne.edu.ar 
Adicionalmente, en el marco del inminente tratamiento de las Apocináceas para el proyecto "Flora Argentina" (Ezcurra et al., inéd.) se ensaya aquí una clave que permite diferenciar los 49 taxones de Oxypetalum documentados para nuestro país, 39 de los cuales se ilustran mediante fotografías de sus flores.

\section{Materiales y Métodos}

Una cámara fotográfica con alta resolución (Sonny DSC-HX400V) y un microscopio estereoscópico (Zeizz Stemi DV4) fueron utilizados para obtener imágenes empleadas en el proceso de estudio del material y para confeccionar las ilustraciones correspondientes a la especie que aquí se describe. El indumento y el polinario fueron examinados con microscopio óptico (Leica DM500) con cámara fotográfica incorporada (ICC50).

En el herbario CTES se estudiaron ejemplares de O. karstenianum, O. molle, $O$. oblanceolatum y $O$. sylvestre. Asimismo, durante exploraciones botánicas se estudió material vivo. Adicionalmente, la revisión de imágenes de alta resolución en páginas web (reflora.jbrj.gov.br; sweetgum.nybg.org, science.mnhn.fr y apps.kew.org) permitieron ampliar la lista de material estudiado de estas especies, incluyendo a los ejemplares tipo de estos nombres. Los acrónimos de los herbarios son citados según Thiers (2018).

\section{Resultados}

Oxypetalum venustum $\mathrm{H}$. A. Keller, sp. nov. Fig. 1, 2 y 5D

Quoad habitum, fabricam inflorescentiorum et coronae lobis forma ad Oxypetalum fontellae $S$. A. Cáceres accedit, sed ab ea differt essentialiter foliis latioribus, floribus majoribus et corpusculum longioribus.

Typus. Argentina. Corrientes: San Miguel, Ruta Nac. 118, $27^{\circ} 42$ ' 58,22' S, 57 13 ' 47,81" W, 73 m, 22-X-2019, fl, Keller \& Fitze 13943 (holotypus CTES!; isotypi SI, K).
Hierba latescente erecta $15-29 \mathrm{~cm}$ alt.; tallos cilíndricos, pubescentes, pelos setosos multicelulares, uniseriados, blanquecinos, 0,2-1,6 mm long.; entrenudos 1,6-4,3 cm long. Hojas opuestas; pecíolos 0,1-1 mm long., con pubescencia similar a la del tallo; láminas cordiformes a lanceoladas, 9-36 × 4-22 mm, verde pálidas, concoloras, epifilo pubescente, con tricomas dispersos más pequeños, 0,2-0,7 $\mathrm{mm}$ long., nervaduras y margen del hipofilo con setas blancas similares a las del pecíolo; margen entero, ondulado, ciliado, base cordada a sub-auriculada con 1-3 coléteres blancos, angostamente cónicos, de 0,4-0,6 mm long. en el epifilo, ápice agudo, venación broquidódroma con 6-10 pares de nervaduras secundarias. Inflorescencias extra-axilares o terminales umbeliformes, ascendentes, alternas, con 1-5 flores; pedúnculos 4,5-12 cm long. $\times 1-1,3 \mathrm{~cm}$ diám., con pubescencia similar a la del tallo; brácteas lineares, pilosas, ciliadas, 0,7-1 $\times$ ca. 0,5 mm; pedicelos 17-24 mm long. $\times$ ca. 0,5 mm diám., pubescentes. Cáliz dividido hasta cerca de la base; tubo 0,5-0,6 mm alt.; lóbulos linear-lanceolados, agudos, 4,2-4,3 × 0,9-1 $\mathrm{mm}$, densamente pubescentes abajo, glabros arriba, ciliados, 1-2 coléteres de 0,3-0,6 mm long. en el seno. Corola verde-violácea, tubo reflexo, 1,8-2 $\mathrm{mm}$ alt. $\times$ 3,8-4 $\mathrm{mm}$ diám., lóbulos linear lanceolados 12-13 × 2,4-2,9 $\mathrm{mm}$, reflexos, retorcidos, algo incurvos en el tercio distal, glabros arriba, pubescentes abajo, tricomas 0,1-0,4 mm long. Corona morada a atropurpúrea, carnosa; segmentos 4-lobulados, 3,8-3,9 × 3,5-3,7 $\mathrm{mm}$, cara interna con dos prominencias hemisféricas cerca del tercio distal y con tricomas simples, no septados, 0,1-0,4 $\mathrm{mm}$ long. en la base, los 2 lóbulos apicales ca. $3 \mathrm{~mm}$ long. unidos en el tercio basal y curvados hacia el ginostegio, lóbulos laterales ca. $2 \mathrm{~mm}$ long. Ginostegio sésil ca. $2 \mathrm{~mm}$ alt. $\times 2 \mathrm{~mm}$ diám. Anteras rectangulares, $1-1,1 \times 0.9-1 \mathrm{~mm}$, membrana apical anchamente ovada, 0,9-1 $\times 1-1,1$ mm. Retináculo linear, 0,8-0,9 × 0,09-0,13 $\mathrm{mm}$, curvado en vista lateral; caudículas horizontales 0,24-0,33 mm long., con dientes subinclusos de ápice redondeado, ca. 0,18 $\mathrm{mm}$; polinias reniformes, $0,48-0,59 \times 0,15$ $0,21 \mathrm{~mm}$. Cabeza estilar pentalobulada, 1-1,1 $\mathrm{mm}$ alt. $\times 1,2 \mathrm{~mm}$ diám., convexa, apéndice 

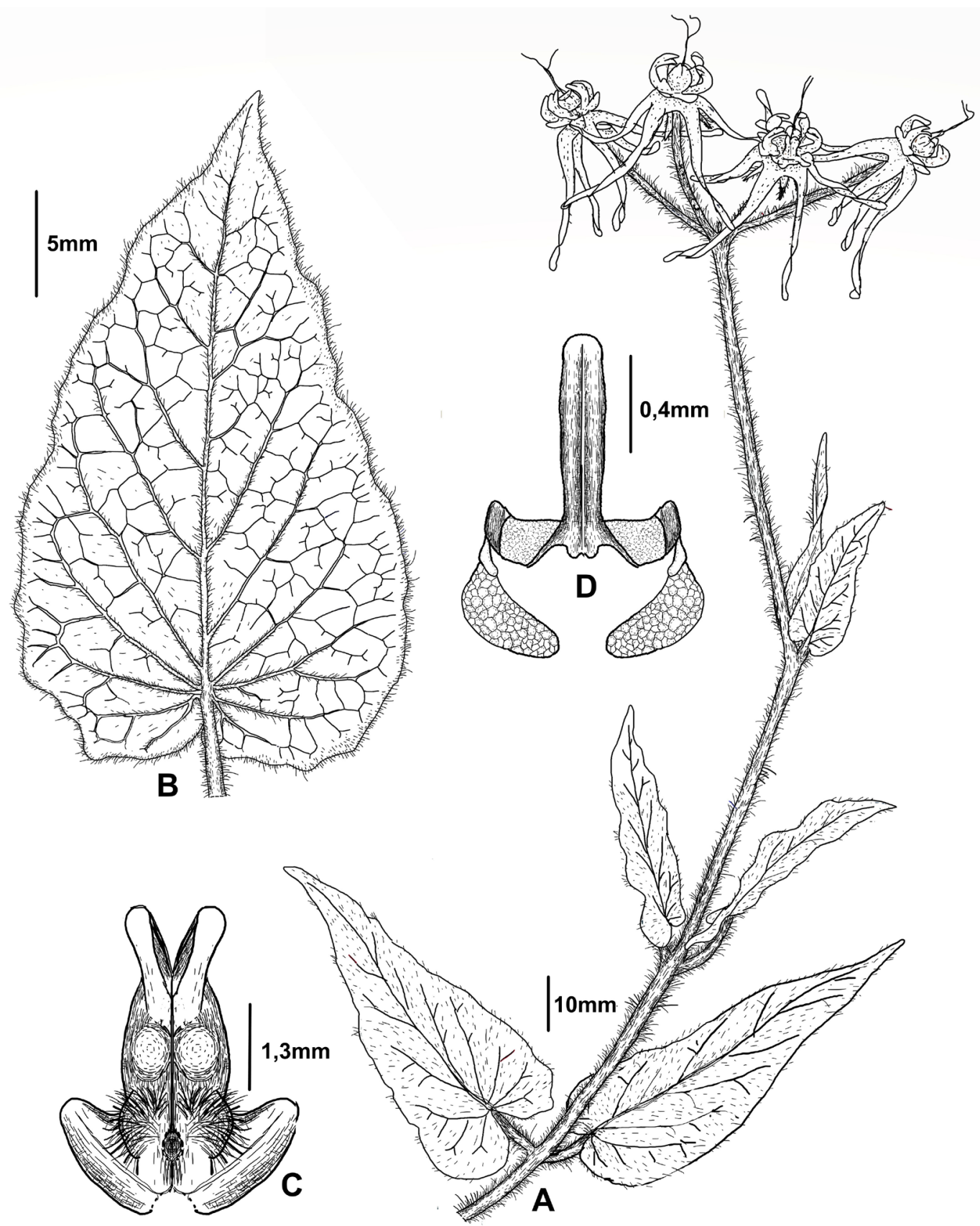

Fig. 1. Oxypetalum venustum. A: Rama florífera. B: Hoja. C: Cara interna del lóbulo de la corona. D: Polinario (Dibujo del autor).

Fig. 1. Oxypetalum venustum. A: Floriferous branch. B: Leaf. C: Internal face of the corona lobe. D: Pollinaria (Drawing by the author).

estigmático morado filiforme de 5,7-6,5 × 0,2 $\mathrm{mm}$, dividido en dos filamentos desde el tercio o el cuarto basal. Ovario dialicarpelar ca. $1 \times$ $0,8 \mathrm{~mm}$, carpelos lisos, incano pubescentes. Folículos desconocidos.
Etimología. Del latín venustus: agraciado, hermoso (Stearn, 2006), en virtud de la elegancia y belleza de sus flores verdevioláceas con la corola totalmente reflexa, dispuestas sobre un follaje verde pálido. 

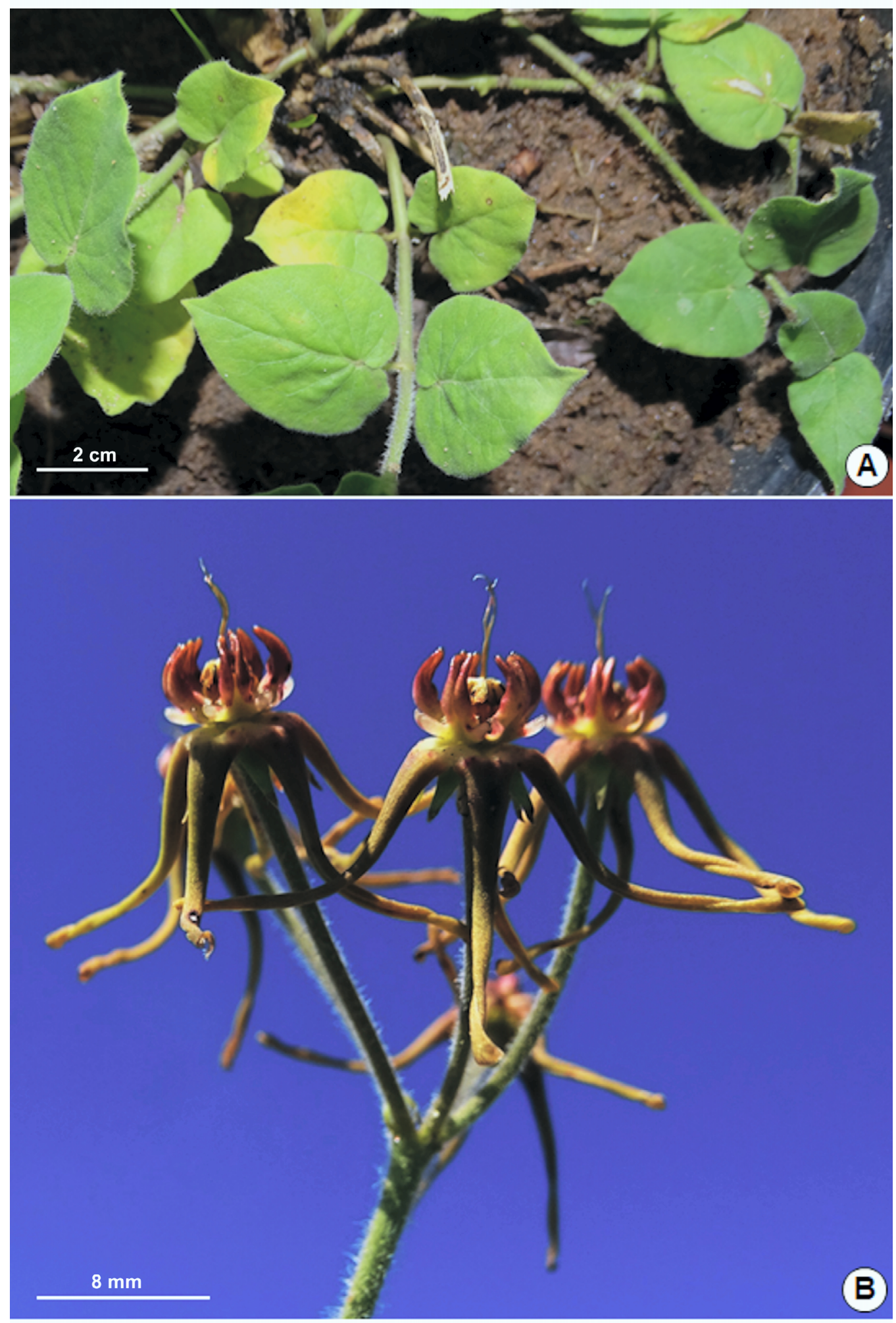

Fig. 2. Oxypetalum venustum. A: Base con hojas. B: Inflorescencia (Fotos del autor).

Fig. 2. Oxypetalum venustum. A: Plant base with leaves. B: Inflorescence (Photographs by the author). 
Hábitat, distribución y estado de conservación. Conocida apenas por el ejemplar tipo, su distribución hasta el presente se restringe a un sector del límite noroeste del Macrosistema Iberá, en la localidad de Loreto, departamento San Miguel, Corrientes, Argentina (Fig. 3), donde crece en estrechos fragmentos remanentes de palmares de Butia paraguayensis (Barb. Rodr.) L. H. Bailey sobre suelo arenoso a $73 \mathrm{~m}$ de altitud. Como es frecuente en zonas con alta incidencia de emprendimientos ganaderos $\mathrm{y}$ forestales a gran escala, la vegetación natural se restringe a franjas muy angostas, las que se sitúan entre la vegetación ruderal típica de bordes de caminos, y los bordes de los monocultivos o las cercas alambradas que limitan el pastoreo. No habiéndose recolectado otras muestras de la especie en un sector altamente modificado de una provincia botánicamente muy explorada, es probable que la especie se encuentre en peligro crítico. Sin embargo, hasta tanto no se efectúen relevamientos para determinar la presencia de otras poblaciones se carecen de datos suficientes para definir su situación de conservación por lo que se incluye provisionalmente a este taxón en la categoría DD (data deficient) siguiendo los lineamientos de IUCN Standards and Petitions Subcommittee (2019).

La belleza y el tamaño relativamente grande de sus singulares flores, así como también su follaje verde pálido, constituyen atributos que le otorgan a esta especie cierto potencial decorativo que podría impulsar su conservación ex situ y el desarrollo de técnicas para la producción de especímenes ornamentales, como ha ocurrido con otras especies del género (Armitage et al., 1990).

Floración. Al recolectar la muestra los ejemplares estaban casi todos con flores abiertas, y muchas se encontraban ya senescentes, por lo que su floración probablemente comience a principios de octubre y se extienda hasta noviembre, aunque dicho rango puede estar influenciado por variables diversas, como por ejemplo las quemas de los pastizales. Las flores liberan una fragancia agridulce después del mediodía y se observó que son visitadas por moscas y avispas.
Observaciones taxonómicas. En Oxypetalum los lóbulos de la corola reflexos son muy frecuentes, tanto en plantas volubles como en erectas. Sin embargo O. venustum presenta además de los lóbulos el tubo corolino totalmente invertido o reflexo luego de la antesis, de tal manera que se presenta convexo, dejando completamente exerta la inserción de las piezas de la corona. Este carácter no se repite en las demás especies del género que hasta el presente se han documentado. Dentro de los taxones volubles, la especie tipo, $O$. banksii Schult., es el representante del género cuyas flores abiertas parecen aproximarse más a este atributo morfológico, sin embargo, como puede observarse en fotos de flores abiertas (ej. Vieira et Fonseca, 2011), la inserción de las piezas de la corona se encuentra levemente inclusa en las cavidades nectaríferas, lo que no ocurre en $O$. venustum.

Oxypetalum venustum crece en un hábitat similar a $O$. fontellae, en palmares de Butia (Becc.) Becc. sobre lomadas arenosas, y ambas presentan un aspecto similar en tamaño y crecimiento. La morfología de las hojas, más anchas que en $O$. fontellae, constituye una diferencia notable, como se indica en la diagnosis. Respecto a las inflorescencias, en $O$. fontellae son también largamente pedunculadas, pero multifloras; las flores son también largamente pediceladas y con tonalidades rojizas, pero más pequeñas. Las piezas de la corona son muy similares, con cuatro lóbulos carnosos, dos laterales y dos apicales; pero si se estudian muestras in vivo se puede observar que los lóbulos apicales se curvan hacia el ginostegio en $O$. venustum y hacia la corola en $O$. fontellae. Los polinarios, aunque distintos en tamaño, son morfológicamente similares en ambas especies, con polinias curvadas hacia adentro, caudículas horizontales anchas con dientes subinclusos de ápice redondeado, sin embargo, el retináculo es linear en $O$. venustum y obovado en $O$. fontellae.

\section{Nuevos sinónimos}

Durante la elaboración de la clave que se incluye en esta contribución se hallaron dificultades para distinguir de manera consistente a Oxypetalum karstenianum (= Schistogyne decaisneana H. Karst.) de $O$. sylvestre $(=S$. sylvestris Hook. \& Arn.), así 
como también a $O$. molle de $O$. oblanceolatum. El estudio exhaustivo de material vivo y de ejemplares de herbario, incluyendo los tipos, así como también la revisión de la literatura disponible sobre estos representantes del género, permiten atribuir tales dificultades a la conespecificidad entre estos taxones de distinción ambigua, por lo que se establece aquí la sinonimia correspondiente.

Oxypetalum sylvestre (Hook. \& Arn.) Goyder \& Rapini, Phytotaxa 26: 13. 2011 (Fig. 8B).

Schistogyne sylvestris Hook. \& Arn., J. Bot. 1: 292. 1834. Typus: "Banda Orientale", sin fecha, J. Baird s.n. (K!).

Schistogyne sylvestris Hook. \& Arn. var. chacoensis Malme, Ark. Bot. 25A(14): 8. 1933.

Schistogyne decaisneana H. Karst., Florae Columbiae 2: 121. 1866. Typus: Brazil. Rio
Grande do Sul: sin localidad, sin fecha, $A$. Isabelle s.n. (P!).

Schistogyne berroi Arechav., Anales Mus. Nac. Montevideo 7: 117. 1910.

Schistogyne sylvestris Decaisne (nom. inval. pro syn.), Meyer Asclepiadaceae. En H. R. Descole (ed.), Gen. Sp. P1. Arg. 2: 133. 1941.

Oxypetalum karstenianum Goyder \& Rapini (syn. nov.), Phytotaxa 26: 13. 2011.

Indumento y devenir taxonómico de la especie. Schistogyne sylvestris Hooker et Arnott (1834: 292), la especie tipo del género Schistogyne Hook. \& Arn., fue descripta sobre la base de material recolectado en Uruguay y Argentina (Entre Ríos) indicándose en el protólogo que se trata de plantas glabras, lo cual resulta llamativo ya que la pubescencia es apreciable a simple vista en el ejemplar tipo, especialmente

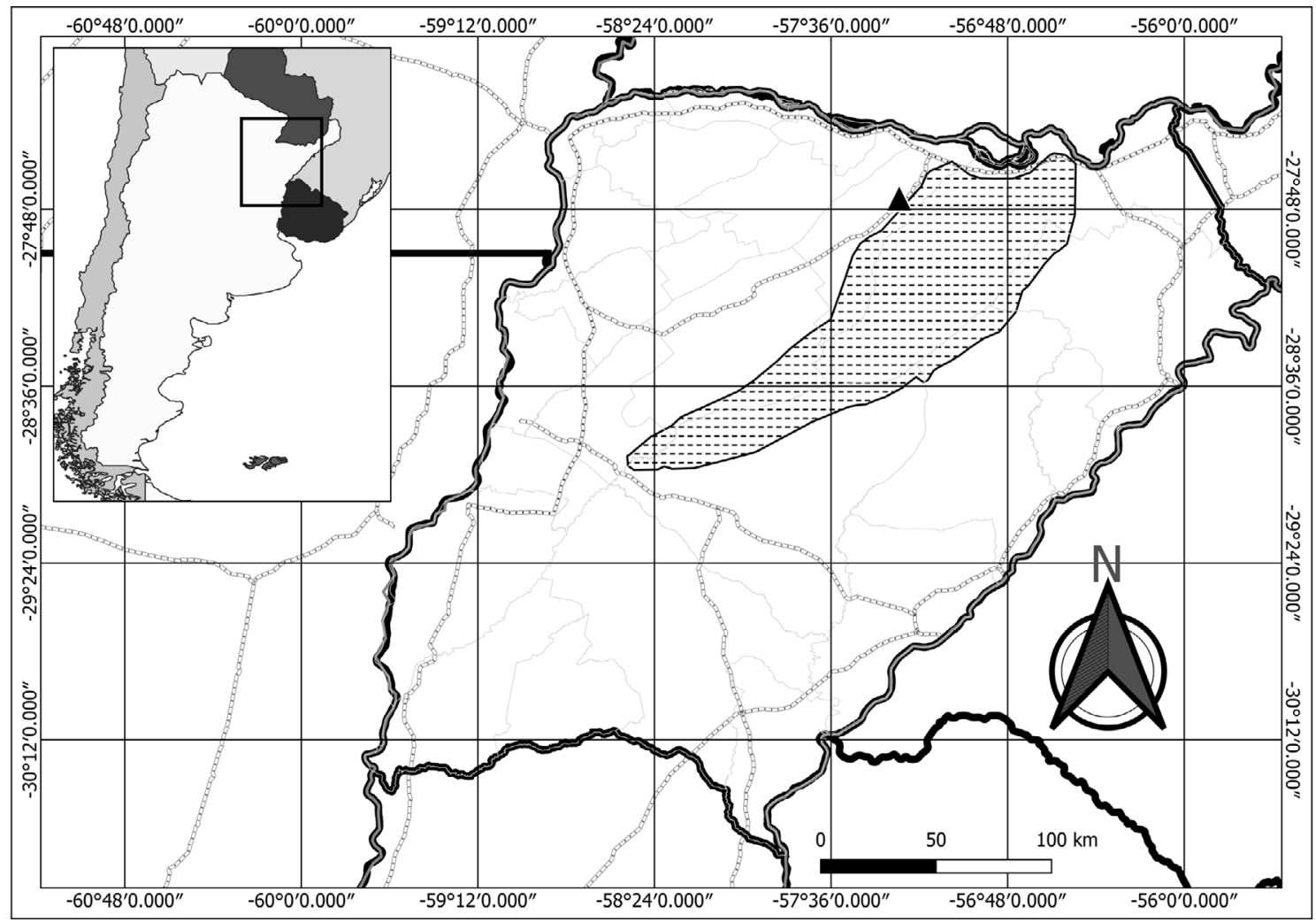

Fig. 3. Mapa de localización de Oxypetalum venustum (triángulo negro).

Fig. 3. Location map of Oxypetalum venustum (black triangle). 
en el ápice de las ramas. Posteriormente, Decaisne (1844) al incluir una muestra recolectada por Arsène Isabelle, en Río Grande do Sul (Brasil), modifica y amplía la descripción del género hasta entonces monotípico, señalando una pubescencia velutina subincana para las hojas, y vellosa para el interior de las flores.

Sobre la base de ese mismo material brasileño Karsten (1866) redacta una breve diagnosis de Schistogyne decaisneana indicando las hojas velutino-pubescentes como único carácter que permite diferenciarla de S. sylvestris, cuya pubescencia foliar describe como minutísimamente "esparsohirtula”. En su descripción ampliada del género señala asimismo un indumento holoseríceo para la cara superior de la corola.

En la obra Genera et Species Plantarum Argentinarum, Meyer (1944) distingue ambas especies en una clave dicotómica en la que señala que Schistogyne sylvestris presenta hojas glabras o con pelos muy escasamente esparcidos y lóbulos de la corola barbados solamente en la base, y que $S$. decaisneana presenta hojas profusamente pubescentes (especialmente en el envés) y lóbulos de la corola barbados hasta la mitad de su longitud. En el tratamiento de esta última especie incluye en la sinonimia un nombre superfluo, $S$. sylvestris Decaisne (non Hooker et Arnott), y en la descripción añade que, en el haz, las hojas presentan pelos esparcidos. En las ilustraciones el autor no incluye los caracteres distintivos de ambas especies.

Malme (1933) describe el taxón Schistogyne sylvestris Hook. \& Arn. var. chacoensis sobre la base de material proveniente del Delta del Paraná y no de la región chaqueña, error que es señalado por Schulz (1937: 380) quien sugiere anular esta variedad indicando que sólo se trataría de un ejemplar lozano del tipo, debido al medio extraordinariamente húmedo donde fue recolectado. Por su parte, el taxón Schistogyne berroi Arechav. se funda sobre la base de caracteres diagnósticos ininteligibles: "inflorescencias, en la axila de las hojas, escalonadas desde las de la base hasta las de la última rama" (Arechavaleta, 1910), lo cual probablemente hace referencia a las inflorescencias alternas, típicas en el género Oxypetalum.

Sobre la base de estudios filogenéticos, en Rapini et al. (2011) se incluye a Schistogyne en la sinonimia de Oxypetalum $\mathrm{y}$ se transfieren a este último género seis especies mediante nuevas combinaciones, y dos mediante nuevos nombres acuñados para evitar homónimos, entre ellos $O$. karstenianum, que aquí se propone como sinónimo.

Durante las campañas de recolección $y$ el examen de material de herbario, he observado que la variabilidad del indumento detallada en los párrafos precedentes, tanto en relación con las hojas como con la corola, se manifiesta con frecuencia entre ejemplares de la misma localidad o población, y a veces en la misma planta. Por ejemplo, la densidad de tricomas en ambas caras de las hojas es variable, desde velutinas en ramas tiernas hasta glabrescentes en ramas adultas. Todo ello, sumado a que los caracteres determinantes para la taxonomía del género, como la estructura de la corona, del ginostegio y del polinario, no ofrecen elementos consistentes de diferenciación, legitiman la sinonimia que aquí se propone.

Material examinado: ARGENTINA. Misiones: Dep. Candelaria, $27^{\circ} 22^{\prime}$ 40,6", S - 55 28' 12,3", 155 m, 11-XII-2013, fl, $H$. A. Keller \& M. M. Franco 11930 (CTES); ídem, $27^{\circ} 29^{\prime} 01,45^{\prime}$ ' S, 55० 43' 43,5” W, 95 m, 22-XI-2017, fl, H. A, Keller \& J. L. Rojas 13703 (CTES); Dep. Capital, $27^{\circ} 38^{\prime}$ 23,8', S, 55 46' 37,5" S, 110 m, 07-XI-2015, fl, $H$. A. Keller \& M. M. Franco 13103 (CTES). Chaco: Dep. San Lorenzo, Villa Berthet, 29-X-1942, A. G. Schulz 3799 (CTES). Corrientes: Dep. Ituzaingó, Establecimiento Santo Domingo, Mogote A, $27^{\circ} 40^{\prime} 38,7^{\prime}$ S, $56^{\circ} 10^{\prime} 56,5$ " W, $112 \mathrm{~m}, 08-\mathrm{II}-2013, \mathrm{fl}, H$. A. Keller et al. 11264 (CTES); Dep. Mercedes, Estancia Rincón del Ombú, 09-II-1960, T. M. Pedersen 5392 (CTES). Entre Ríos: sin localidad, sin fecha, J. Tweedie 219 (K!); Dep. Colón, Parque Nacional EL Palmar, $31^{\circ} 51^{\prime} 21^{\prime}$ 'S, 58 $18^{\circ} 48^{\prime}, \mathrm{W}, 13-\mathrm{XII}-$ 
2014, fl, M. S. Ferrucci et al. 3192 (CTES); camino al Río Uruguay, $31^{\circ} 52^{\prime} 07,8$ ' $\mathrm{S}$, $58^{\circ} 14$ ' 44,7' W, 20-IV-2013, fl, Dematteis et al. 4395 (CTES). URUGUAY. "Banda Orientale", no date, J. Baird s.n. (K!); sin localidad, sin fecha, J. Tweedie s.n. (K!).

Oxypetalum molle Hook. \& Arn., J. Bot. 1: 289. 1834. Gothofreda mollis (Hook. et Arn.) O. Kuntze, Revis. Gen. P1. 2: 420. 1891. Typus: St. Catherine, Tweedie 231 (K000096141!, isotypus E00265199!) (Fig. 9B).

Oxypetalum nigrescens Fourn., in Martius, F1. Bras. 6(4): 264. 1885. Gothofreda nigrescens (Fourn.) O. Kuntze, Revis. Gen. P1. 2: 420. 1891.

Oxypetalum suaveolens Fourn., in Martius, F1. Bras. 6(4): 264. 1885. Gothofreda suaveolens (Fourn.) O. Kuntze, Revis. Gen. P1. 2: 420. 1891.

Oxypetalum henschenii Malme, Kongl. Svenska Vetenskapsakad. Handl. 34(7): 45. 1900.

Oxypetalum oliganthum Malme, Kongl. Svenska Vetenskapsakad. Handl. 34(7): 46. 1900.

Oxypetalum hirsutulum K. Schum., Bot. Jahrb. 30(67): 31. 1901.

Oxypetalum campanulatum HandelMazzetti, Akad. Wiss. Wien., Math. -Naturwiss. K1., Denksch r. 79(2): 381. 1931.

Oxypetalum oblanceolatum Farinaccio \& Mello-Silva (syn. nov.), Novon 16: 236238. 2006. Typus: Brazil. Paraná; Cândido de Abreu, Três Bicos, G. Hatschbach 24431 (holotypus, SPF; isotypus, MBM!).

Observaciones. Se trata de una especie cuya distribución abarca los estados brasileños de Goiás, Minas Gerais, Río de Janeiro, São Paulo, Paraná, Santa Catarina y Río Grande do Sul. En Paraguay ha sido recolectada en el departamento Alto Paraná. Fue citada para la Argentina (Misiones) como O. molle por Cáceres (1989) y como $O$. oblanceolatum por Farinaccio et Keller (2014).

Es una especie polimórfica cuyo nombre presenta numerosos sinónimos, como ocurre con muchos taxones ampliamente distribuidas de la subfamilia Asclepiadoideae. Sus hojas son variables en tamaño y forma, elípticas, ovadas, obovadas, así como también en indumento, desde pubérulas (Keller \& Franco 11936) a incanas (Perez Moreau 21193). La corola es variable en tonalidad y coloración exhibiendo algunos especímenes los lóbulos blancos, mientras que en otros son verdes, verde amarillentos o rojizos. La textura de la corola también puede ser variable, presentando algunas veces una superficie adaxial algo verrucosa, lo cual, entre otros caracteres ha dado lugar a la conformación de la sección Orthodes, dentro de la que Fournier (1885: 264) aglutinaba dos taxones que luego pasaron a ser sinónimos de $O$. molle.

Material examinado: ARGENTINA. Misiones: Dep. Gral. Manuel Belgrano, Campiñas de Américo, $26^{\circ} 16^{\prime} 44,6$ " S, $53^{\circ}$ 42' 23,7' W, 797 m, 12-XI-2014, fl, H. A. Keller et al. 12370 (CTES); Dep. Montecarlo, Colonia Guatambú, $26^{\circ} 35^{\prime}$ 10,12 'S, 54 40' 51,15” W, $206 \mathrm{~m}, 29-\mathrm{X}$ 2019, fl, H. A. Keller 13944 (CTES); Dep. Guaraní, Predio Guaraní, Tramo I, 08-XII2001, fl, H. A. 1471 (CTES); Aldea aborigen Caramelito, 15-XI-2006, fl, H. A. Keller \& G. T. Prance 3375 (CTES, K); Dep. Cainguás, Arroyo La Cruz al km 284 (Ruta 14), 26-VII-1937, fl, Perez Moreau 21193 (LIL); Dep. Candelaria, $27^{\circ} 22^{\prime}$ 40,6' S, $55^{\circ}$ 28' 12,3" W, 155 m, 11-II-2013, fl, fr, $H$. A. Keller \& M. M. Franco 11936 (CTES). BRAZIL. Paraná: Cândido de Abreu, Três Bicos, 09-VII-1970, fl, G. Hatschbach 24431 (MBM).

\section{Conclusiones}

La revisión bibliográfica y las novedades aquí presentadas permiten concluir que hasta el presente la flora de nuestro país cuenta con un total de 47 especies de Oxypetalum, o bien 49 taxones si consideramos categorías infraespecíficas. De estos, 20 corresponden a plantas volubles y 29 a erectas o decumbentes. La siguiente clave permite diferenciarlas. 


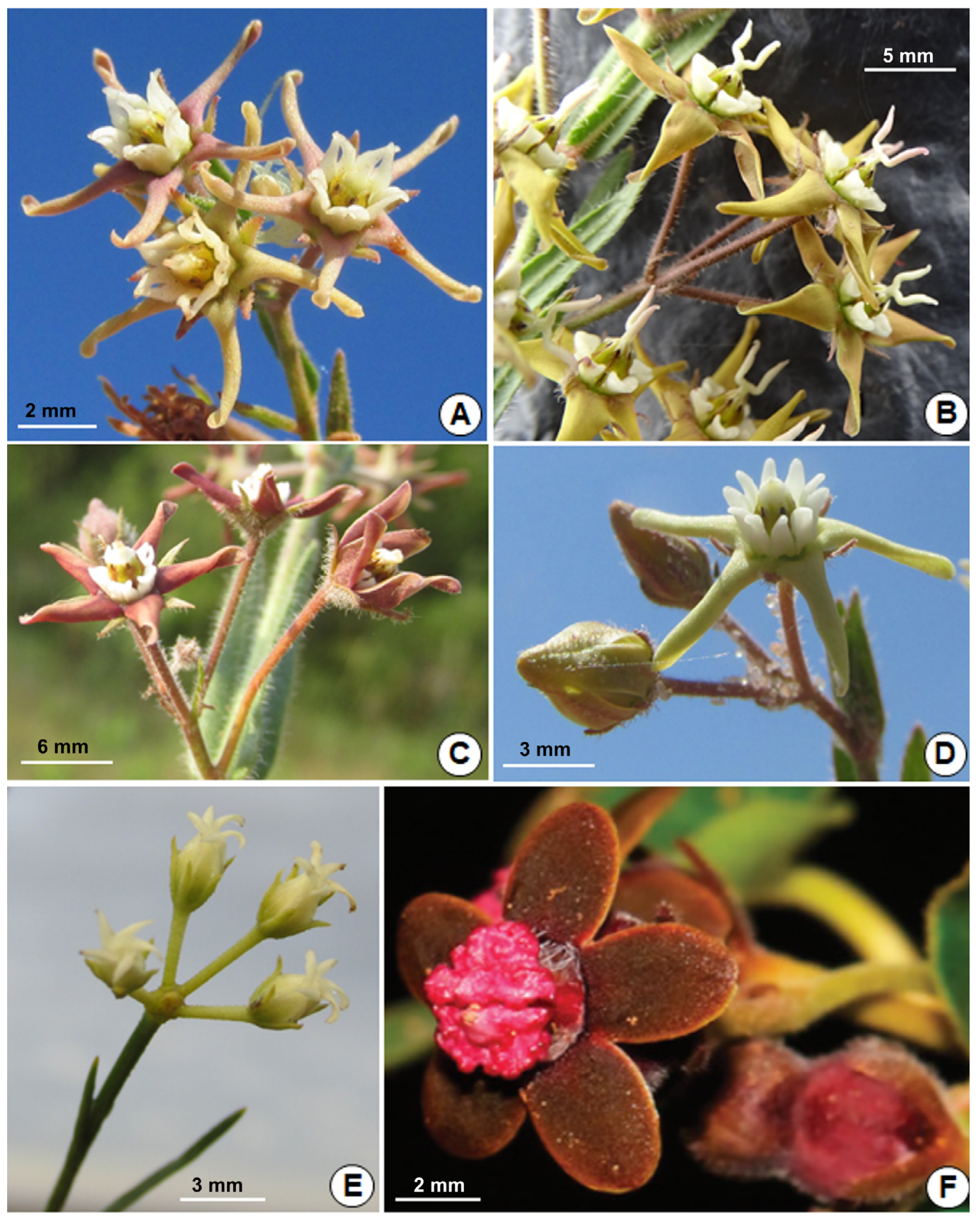

Fig. 4. A: Oxypetalum microphyllum. B: O. argentinum. C: O. radinsii. D: O. humile. E: O. corymbosum. F: $O$. globosum (Fotos A-E: autor; F: Claudia Martín).

Fig. 4. A: Oxypetalum microphyllum. B: O. argentinum. C: O. radinsii. D: O. humile. E: O. corymbosum. F: $O$. globosum (Photographs A-E: author; F: Claudia Martín). 


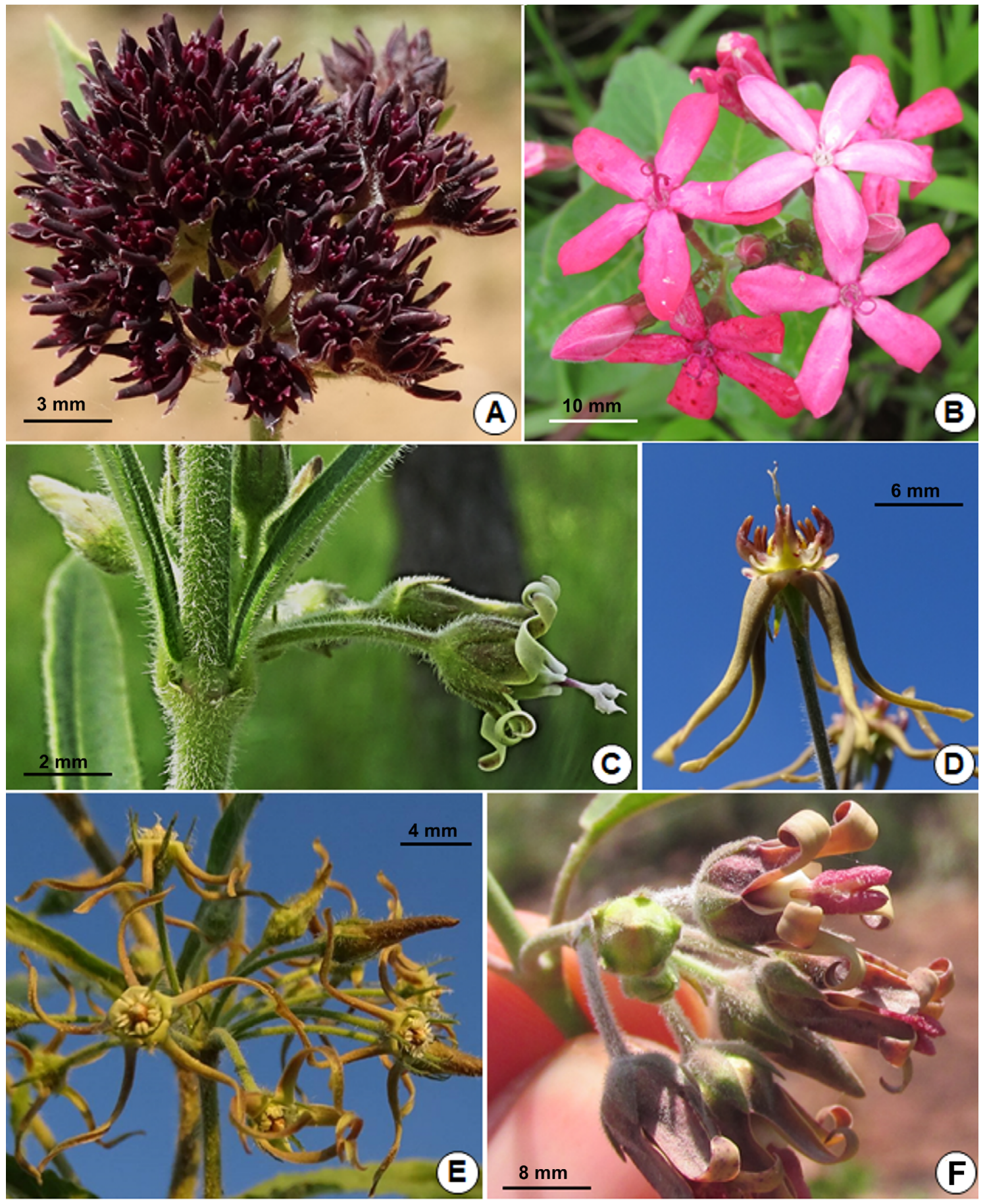

Fig. 5. A: Oxypetalum commersonianum. B: O. coccineum. C: O. joergensenii. D: O. venustum. E: O. fontellae. F: O. teyucuarense (Fotos A: Leonardo Deble; B-F: autor).

Fig. 5. A: Oxypetalum commersonianum. B: O. coccineum. C: O. joergensenii. D: O. venustum. E: O. fontellae. F: O. teyucuarense (Photographs A: Leonardo Deble; B-F: author). 


\section{Clave para identificar las especies de Oxypetalum de la Argentina}

A. Plantas erectas o decumbentes.

B. Láminas foliares menos de $2 \mathrm{~cm}$ long., ovadas a lanceoladas.

C. Plantas decumbentes; lóbulos del cáliz de hasta 1,8 mm long.; lóbulos de la corola de hasta $3 \mathrm{~mm}$ long. O. microphyllum Hook. \& Arn. (Fig. 4A)

$\mathrm{C}^{\prime}$. Plantas erectas, lóbulos del cáliz nunca menores a $2 \mathrm{~mm}$ long.; lóbulos de la corola de más de 4 mm long.

D. Piezas de la corona con lóbulos tortuosos en la cara ventral, falcados en la cara dorsal, cabeza estilar exerta.

E. Apéndice estigmático con segmentos ca. $4 \mathrm{~mm}$ long., caudículas con espesamientos obscuros sólo arriba de la inserción de las polinias. O. argentinum Malme (Fig. 4B)

E'. Apéndice estigmático con segmentos menores, diminutos, espesamientos a lo largo de la caudícula. O. radinsii H. A. Keller (Fig. 4C)

D'. Piezas de la corona con lóbulos recurvos agudos, cabeza estilar inclusa.

O. humile (Morong) Hassl. (Fig. 4D)

$\mathrm{B}^{\prime}$. Láminas foliares más de $2 \mathrm{~cm}$ long., cuando menores no ovadas ni lanceoladas.

F. Caudículas edentadas.

G. Plantas palustres, hojas lineares. O. corymbosum (Malme) Liede \& Meve (Fig. 4E)

G'. Plantas no palustres, hojas no lineares.

H. Tubo de la corola globoso. O. globosum C. Ezcurra \& C. M. Martín (Fig. 4F)

H'. Tubo de la corola nunca globoso.

I. Inflorescencias multifloras, compactas, caudículas horizontales anchas.

O. commersonianum (Decne.) Fontella \& E. A. Schwarz (Fig. 5A)

I'. Inflorescencias paucifloras, laxas, caudículas oblicuas. ..... O. coccineum Griseb. (Fig. 5B)

$\mathrm{F}^{\prime}$. Caudículas dentadas.

J. Piezas de la corona con apéndice ventral (lígula).

K. Apéndice estigmático dividido hacia el ápice en dos anchos lóbulos trilobados, lígula de la corona más corta que los lóbulos laterales.

O. joergensenii T. Mey. (Fig. 5C)

$\mathrm{K}^{\prime}$. Apéndice estigmático corto, incluso, lígula de la corona más larga que los lóbulos laterales... O. incanum E. Fourn.

J'. Piezas de la corona sin lígula.

L. Piezas de la corona con 4 lóbulos, dos laterales y dos apicales.

M. Inflorescencias paucifloras, corola con el tubo reflexo mostrando la inserción de la corona, retináculo linear.

O. venustum H. A. Keller (Fig. 5D)

M'. Inflorescencias densifloras, corola con el tubo no reflexo, inserción de la corona inclusa, retináculo obovado. O. fontellae S. A. Cáceres (Fig. 5E)

L'. Piezas de la corona enteras o diversamente bilobadas.

N. Piezas de la corona no bilobadas.

Ñ. Apéndice estigmático ruminado, largamente exerto.

O. teyucuarense Farinaccio \& H. A. Keller (Fig. 5F)

Ñ'. Apéndice estigmático liso, subincluso.

O. arnottianum H. Buek. (Fig. 6A)

N'. Piezas de la corona más o menos profundamente bilobadas.

O. Hojas lineares, de hasta $5 \mathrm{~mm}$ lat.

P. Piezas de la corona partidas casi hasta la base. 
Q. Corona totalmente inclusa.

R. Apéndice estigmático cilíndrico, igual o subigual en altura a las piezas de la corona. O. lynchianum T. Mey. (Fig. 6B)

R'. Apéndice estigmático ovoide, notablemente más corto que las piezas de la corona. O. chodatianum Malme (Fig. 6C)

Q'. Corona con el ápice exerto. O. schulzii Malme

P'. Piezas de la corona partidas hasta ca. la mitad o más arriba.

$\mathrm{S}$. Hojas de hasta $1 \mathrm{~mm}$ lat., retináculo breve, apenas excediendo el ancho de las caudículas. O. gracile T. Mey. (Fig. 6D)

S'. Hojas más anchas, retináculo mucho más largo que el ancho de las caudículas.

T. Apéndice estigmático terminado en dos filamentos, generalmente divergentes. O. arenicola Hauman ex Lillo

$\mathrm{T}^{\prime}$. Apéndice estigmático cónico, breve. O. hilarianum E. Fourn.

O'. Hojas no lineares, más anchas.

U. Apéndice estigmático exerto por sobre la corona.

V. Apéndice estigmático con ápice carnoso, grueso.

W. Láminas elípticas a subovales, ápice redondeado mucronulado a agudo, base subcordiforme; apéndice estigmático ciatiforme.

.. O. capitatum Mart. subsp. mirabile (Malme) Fontella \& Farinaccio (Fig. 5E)

W'. Láminas lineares, lanceoladas a oblongas, ápice agudo a acuminado; apéndice estigmático bífido solamente en el ápice. . O. capitatum Mart. subsp. capitatum

$\mathrm{V}^{\prime}$. Apéndice estigmático con ápice o ramas filiformes.

X. Retináculo notablemente más largo que las polinias. O. solanoides Hook. \& Arn. (Fig. 6F)

$X^{\prime}$. Retináculo más corto que las polinias.

Y. Corola con lóbulos lanceolados a linear-lanceolados 5-7 x ca. 1,5 mm, apéndice estigmático dividido en el ápice en dos lóbulos conniventes O. crispum Wight ex Hook. \& Arn. (Fig. 7A)

$\mathrm{Y}^{\prime}$. Corola con lóbulos filiformes retorcidos, 10-12 x ca. $1 \mathrm{~mm}$, apéndice estigmático dividido en ramas divergentes.

Z. Apéndice estigmático con ramas sensiblemente más cortas que la porción basal. .......... O. parviflorum (Decne.) Decne. var. parviflorum (Fig. 7B)

Z'. Apéndice estigmático con ramas largas, subiguales a la porción basal. O. parviflorum var. kulmanii W. Hoehne (Fig. 7C)

U'. Apéndice estigmático incluso bajo la corona.

AA. Segmentos de la corona partidos hasta cerca de la base.

O. subcapitatum Malme

AA'. Segmentos de la corona partidos en el ápice.

BB. Retináculo del mismo largo que las polinias. O. charrua $\mathrm{T}$. Mey.

BB'. Retináculo notablemente más largo que las polinias.

O. confusum Malme (Fig. 7D)

A'. Plantas volubles.

CC. Retináculo con un apéndice membránaceo en el ápice. O. appendiculatum Mart. (Fig. 7E)

CC'. Retináculo sin tales características.

DD. Apéndice estigmático dividido en más de 2 lóbulos anchos, lineales o subulados. 
EE. Corola con lóbulos triangulares de menos de $5 \mathrm{~mm}$ long.

O. tucumanense (T. Mey.) Goyder \& Rapini

EE'. Corola con lóbulos de mayor longitud.

FF. Apéndice estigmático dividido en dos ramas trífidas. O. guaraniticum Malme

FF'. Apéndice estigmático con 5-7 ramas filiformes.

GG. Lóbulos de la corola 1,5 cm long. o más largos.... O. mosenii (Malme) Malme (Fig. 7F)

GG'. Lóbulos de la corola menores.

HH. Retináculo visiblemente más corto que las polinias.

O. fiebrigii (Malme) Goyder \& Rapini (Fig. 8A)

HH'. Retináculo más largo que las polinias.

II. Retináculo (0,4 $\mathrm{mm}$ long.) apenas más largo que las polinias $(0,35 \mathrm{~mm}$ long.).

O. pubescens (Malme) Goyder \& Rapini

II'. Retináculo notablemente más largo que las polinias.

JJ. Hojas 4,6 cm lat., base profundamente cordada, pecíolo 2-3 cm long. O. longipedunculatum (Malme) Goyder \& Rapini

JJ'. Hojas hasta $3 \mathrm{~cm}$ lat., base no profundamente cordada, pecíolo excepcionalmente hasta $2 \mathrm{~cm}$ long. ............. O. sylvestre (Hook. \& Arn.) Goyder \& Rapini (Fig. 7B)

DD'. Apéndice estigmático bífido, bilobado o ausente.

KK. Cabeza estilar sin apéndice estigmático. O. megapotamicum Spreng. (Fig. 8C)

KK'. Apéndice estigmático presente.

LL. Caudículas edentadas.

MM. Corola con tubo cilíndrico.

NN. Lóbulos de la corola de $2 \mathrm{~cm}$ long.

O. barberoanum T. Mey. (Fig. 8D)

NN'. Lóbulos de la corola más cortos. O. erianthum Decne. (Fig. 8E)

MM'. Corola con tubo campanulado.

ÑÑ. Hojas ovado-lanceoladas, apéndice estigmático con filamentos retorcidos en el ápice. O. brachystemma Malme (Fig. 8F)

ÑÑ'. Hojas oblongo-lanceoladas, apéndice estigmático con filamentos no retorcidos.

O. macrolepis (Hook. \& Arn.) Decne. (Fig. 8G)

LL'. Caudículas dentadas.

OO. Corona inclusa en el tubo de la corola, no visible, caudículas con dientes inclusos.

PP. Lóbulos de la corola reflexos, de hasta $6 \mathrm{~mm}$ long. O. ostenii Malme (Fig. 8H) PP'. Lóbulos de la corola no reflexos, de más de $1 \mathrm{~cm}$ long. ... O. stipatum Malme (Fig. 9A) OO'. Corona exerta, caudículas con dientes prominentes

QQ. Piezas de la corona con apéndice ventral (lígula).... O. molle Hook. \& Arn. (Fig. 9B) QQ'. Piezas de la corona sin lígula.

RR. Apéndice estigmático craso, trunco, con el ápice levemente hendido. O. sublanatum Malme (Fig. 9C)

RR'. Apéndice estigmático bífido.

SS. Pubescencia lanosa en tallos, hipofilo y frutos.

O. pannosum Decne. var. pannosum (Fig. 9D)

SS'. Plantas sin pubescencia lanosa en las partes indicadas.

TT. Al menos dos tercios de la corona incluidos en el tubo de la corola, frutos corrugados. O. wightianum Hook. \& Arn. (Fig. 9E)

TT'. Corona exerta a excepción de su base, frutos lisos. 


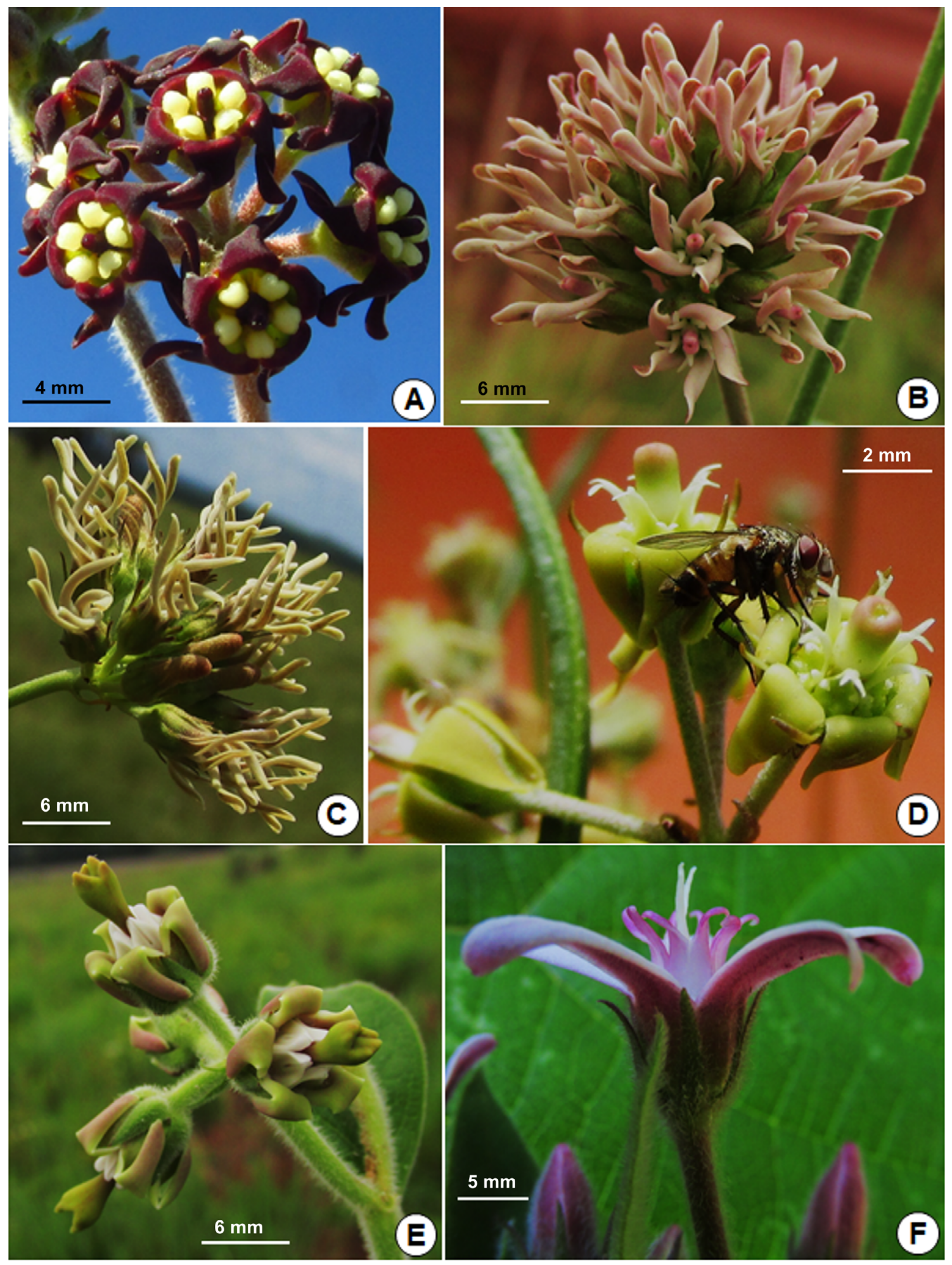

Fig. 6. A: Oxypetalum arnottianum. B: O. lynchianum. C: O. chodattianum. D: O. gracile. E: O. capitaum. F: O. solanoides (Fotos A-F: autor).

Fig. 6. A: Oxypetalum arnottianum. B: O. lynchianum. C: O. chodattianum. D: O. gracile. E: O. capitaum. F: O. solanoides (Photographs A-F: author). 


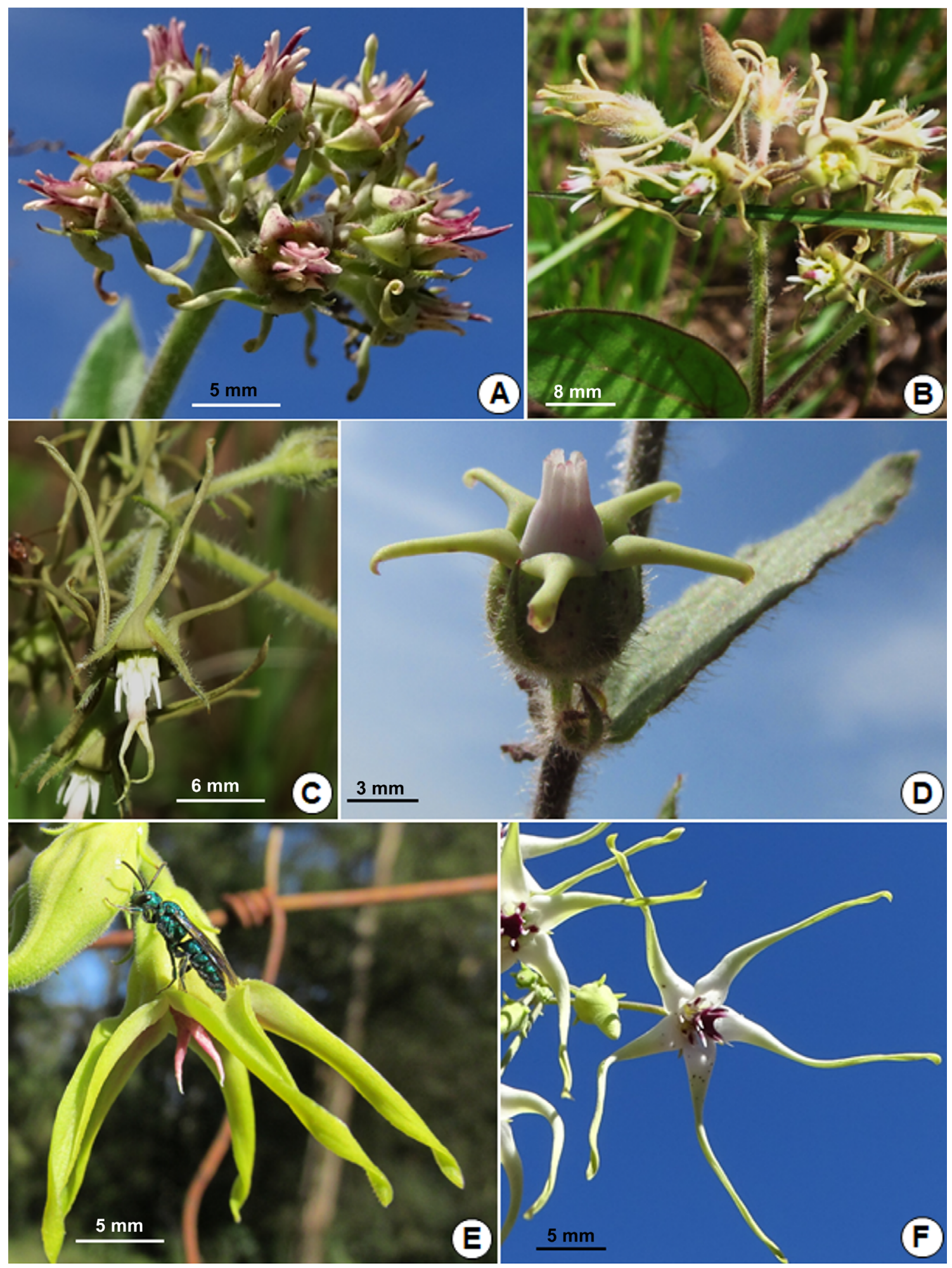

Fig. 7. A: Oxypetalum crispum. B: O. parviflorum var. parviflorum. C: O. parviflorum var. kulmanii. D: O. confusum. E: O. appendiculatum. F: O. mosenii (Fotos A, D-F: autor; B: Cleusa Vogel; C: Leonardo Deble).

Fig. 7. A: Oxypetalum crispum. B: O. parviflorum var. parviflorum. C: O. parviflorum var. kulmanii. D: O. confusum. E: O. appendiculatum. F: O. mosenii (Photographs A, D-F: author; B: Cleusa Vogel; C: Leonardo Deble). 

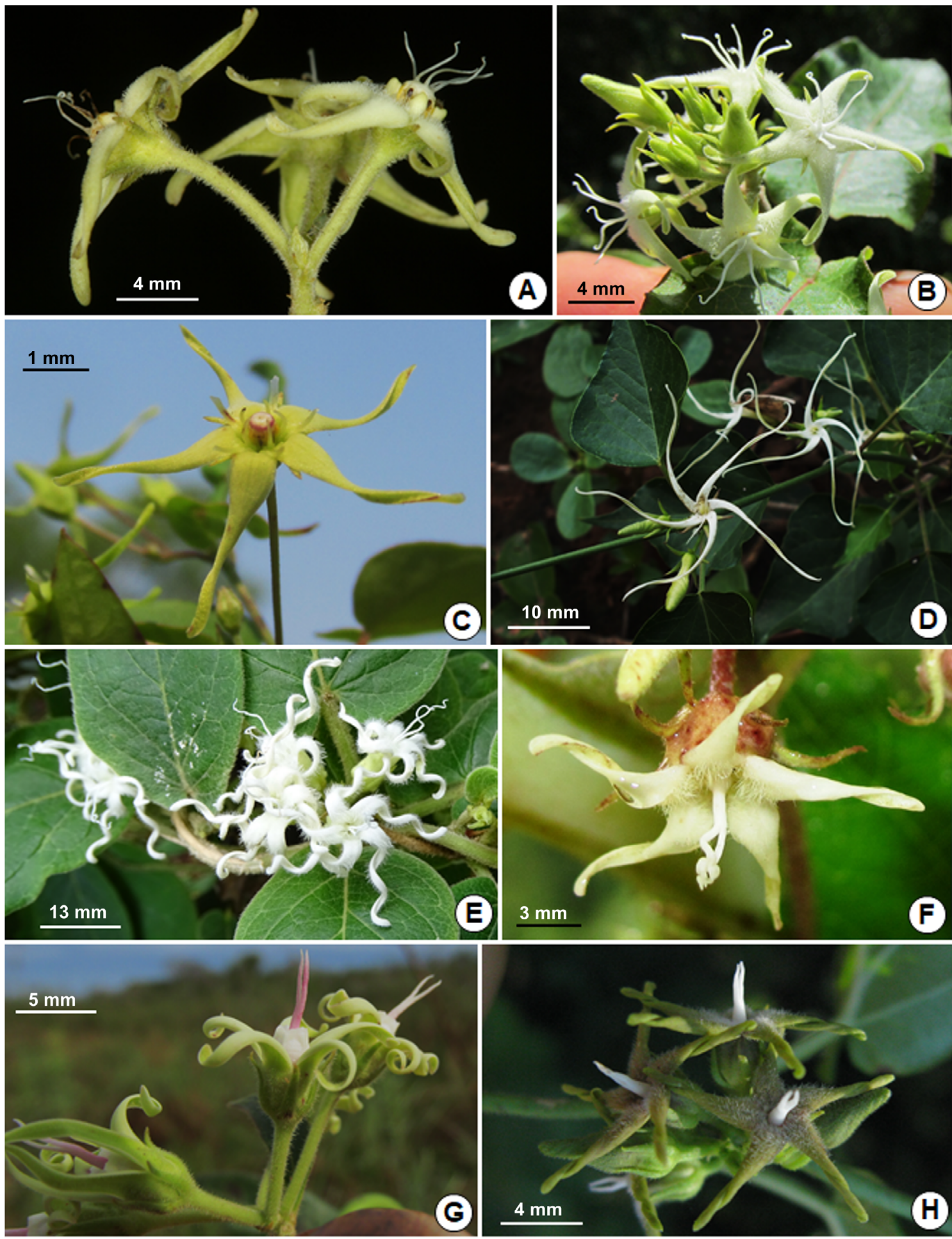

Fig. 8. A: Oxypetalum fiebrigii. B: $O$. sylvestre. C: $O$. megapotamicum. D: $O$. barberoannum. E: $O$. erianthum. F: $O$. brachystemma. G: O. macrolepis. H: O. ostenii (Fotos A: Fernando Zuloaga; D: Ulf Drechsel; F; Gustavo Hildt; B, C, G, H: autor). Fig. 8. A: Oxypetalum fiebrigii. B: O. sylvestre. C: O. megapotamicum. D: O. barberoannum. E: O. erianthum. F: $O$. brachystemma. G: O. macrolepis. H: O. ostenii (Photographs A: Fernando Zuloaga; D: Ulf Drechsel; F; Gustavo Hildt; B, C, G, H: author). 


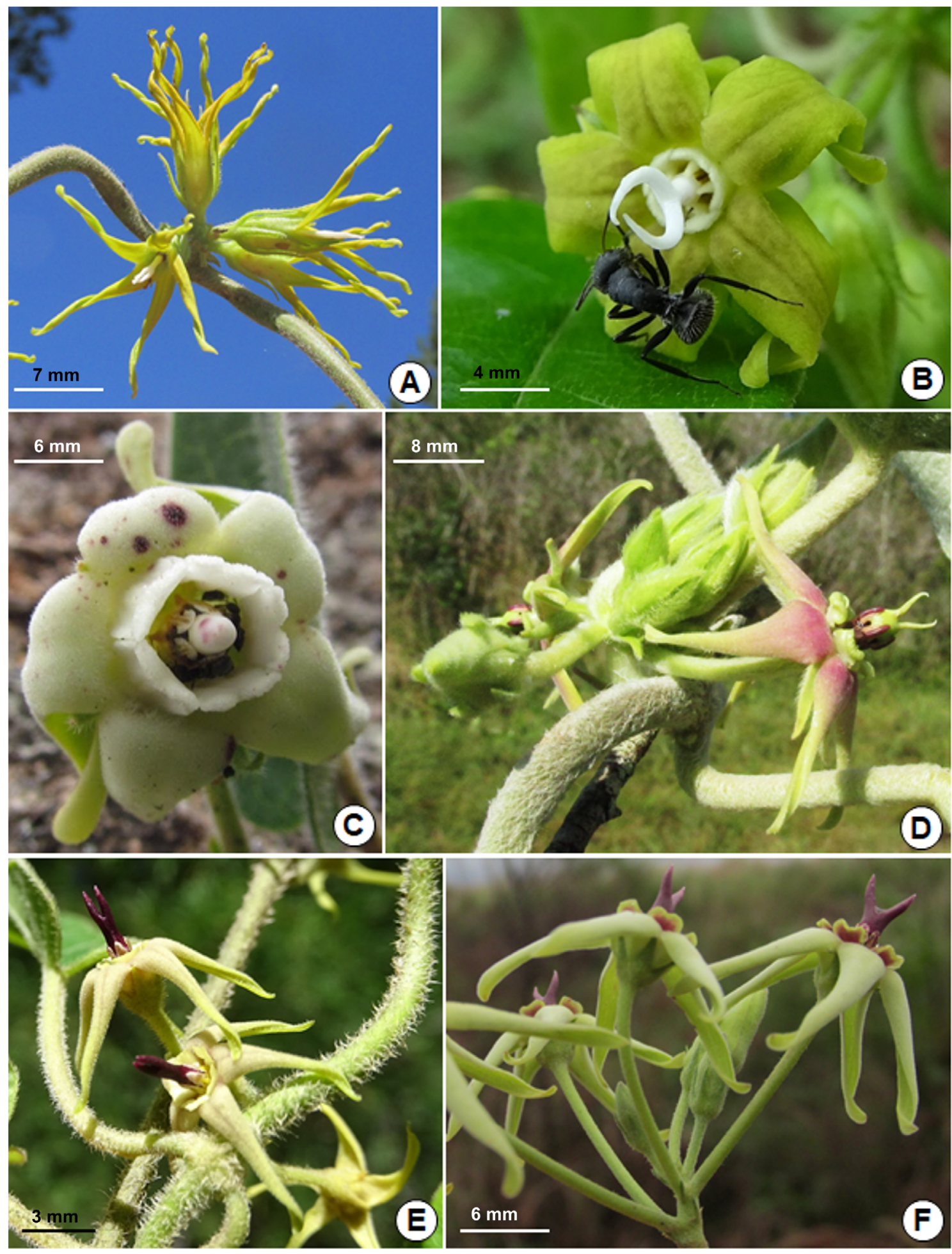

Fig. 9. A: Oxypetalum stipatum. B: O. molle. C: O. sublanatum. D: O. pannosum. E: O. wightianum. F: O. balansae (Fotos A-B, D-F: autor; C: Luis Funez).

Fig. 9. A: Oxypetalum stipatum. B: O. molle. C: O. sublanatum. D: O. pannosum. E: O. wightianum. F: O. balansae (Photographs A-B, D-F: author; C: Luis Funez). 


\section{Agradecimientos}

Se agradece a la Lic. Sara G. Tressens (IBONE) por la lectura del manuscrito. A Naldo Pellizer (FCF-UNaM) por las microfotografías que facilitaron el estudio de los tricomas y el polinario. A Héctor J. Fitze (FCF-UNaM) por su ayuda durante las campañas de recolección. A José L. Rojas (IBONE) por el mapa de localización de la especie. A Leonardo Deble (UNIPAMPA), Cleusa Vogel (UFRGS), Fernando Zuloaga (IBODA), Ulf Drechsel (PyBio), Luis Funez (FURB) y Claudia Martín (Lillo) por el envío de fotografías que ilustran algunas figuras.

\section{Bibliografía}

ARECHAVALETA, J. (1910). Asclepiadáceas. En Flora Uruguaya 4, pp. 82-127, figs. 21-38. ed. J. Arechavaleta. Montevideo: Museo Nacional.

ARMITAGE, A., M. N. G. SEAGER, I. J. WARRINGTON, D. H. GREER \& J. REYNGOUD. (1990). Response of Oxypetalum caeruleum to irradiance temperature, and photoperiod. Journal of the American Society for Horticultural Science. Ser. 115: 910-914. https://doi.org/10.21273/JASHS.115.6.910

CÁCERES MORAL, S. A. (1989). Nuevas citas de Asclepiadaceae para Argentina. Bonplandia 6: 173182. https://doi.org/10.30972/bon.62-31514

CÁCERES MORAL, S. A. (1993). Dos nuevas especies de Oxypetalum y Marsdenia (Asclepiadaceae) de Argentina. Bonplandia 7: 31-38.

https://doi.org/10.30972/bon.71-41426

DECAISNE, J. (1844). Asclepiadaceae. En CANDOLLE, A. L. P. P. (ed.), Prodromus Systematis Naturalis Regni Vegetabilis, vol. 8, pp. 490-665. Treuttel \& Würtz, Paris.

EZCURRA, C. (1999). Asclepiadaceae. En ZULOAGA, F. O. \& O. MORRONE (eds.), Catálogo de las Plantas Vasculares de Argentina, vol. 2, pp. 78-98. Saint Louis: Missouri Botanical Garden Press.

EZCURRA, C., J. FONTELLA PEREYRA \& L. KINOSHITA. (2008). Apocynaceae (incl. Asclepiadaceae). En ZULOAGA, F. O., O. MORRONE \& M. BELGRANO (eds.), Catálogo de las Plantas Vasculares del Cono Sur, vol. 2. Monogr. Syst. Bot. Missouri Bot. Gard. 107: 10901143.
FARINACCIO, M. A. \& H. A. KELLER. (2014). Novelties in Oxypetalum (ApocynaceaeAsclepiadoideae) for the Argentine flora. Phytotaxa 184: 109-114.

https://doi.org/10.11646/phytotaxa.184.2.3

FOURNIER, E. (1885). Asclepiadaceae. En MARTIUS, C. F. P. \& A. W. EICHLER (eds.), Flora Brasiliensis, vol. 6, part 4, pp. 189-332, t. 50-98. Lindauer, München.

HOOKER, W. J. \& G. A. W. ARNOTT. (1834). Contributions towards a flora of South America and the islands of the Pacific. 1. Extra-tropical South America. Journal of Botany, being a second series of the Botanical Miscellany 1: 276-296

IUCN STANDARDS AND PETITIONS SUBCOMMITTEE. (2019). Guidelines for Using the IUCN Red List Categories and Criteria. Version 14. Prepared by the Standards and Petitions Subcommittee. Downloadable from http://www. iucnredlist.org/documents/RedListGuidelines.pdf.

KARSTEN, G. K. W. H. (1866). Florae Columbiae terraumque adjacentium specimina selecta in peregrinatione duodecim annorum observata delineavit et descripsit, vol. 2, part 4, pp. 115-154, t. 161-180. Ferdinand Duemmler Successores, Berlin.

KELLER, H. A. (2015). Oxypetalum radinsii (Apocynaceae: Asclepiadoideae), una nueva especie endémica de Misiones, Argentina. Bonplandia 24: 51-56. https://doi.org/10.30972/bon.241209

KELLER, H. A. \& S. CÁCERES MORAL. (2018). Oxypetalum chodatianum (Apocynaceae) en el Nordeste Argentino. Paraguay Biodiversidad 5: 49-51.

LIEDE S. \& U. MEVE. (2015). Synonymy of three South American genera in Apocynaceae, and new combinations in Oxypetalum and Tassadia. Phytotaxa 202: 035-044. https://doi.org/10.11646/phytotaxa.202.1.4

MALME, G. O. A. (1921). Asclepiadaceae Riograndenses adjectis notulis de ceteris Asclepiadaceis in Brasilia extratropica, Uruguay et Misiones collectis. Arkiv för Botanik 16: 29-30.

MALME, G. O. A. (1933). Die gattung Schistogyne Hook. et Arn. Arkiv för Botanik utgivet av Kongliga Svenska Vetenskapsakademien 25A: 1-15.

MARTÍN, C., C. A. ZANOTTI \& C. EZCURRA. (2017). A New Species of Oxypetalum (Apocynaceae, Asclepiadoideae) from Northern Argentina. Systematic Botany 42: 578-583. https://doi.org/10.1600/036364417X696050 
MEYER, T. (1943). Revisión de las especies argentinas del género Oxypetalum (Asclepiadaceae). Lilloa 9: 5-72.

MEYER, T. (1944). Asclepiadaceae. En DESCOLE, H. R., Genera et Species Plantarum Argentinarum. v. 2, p. 1-273, est. 1-121. Buenos Aires, Guilherme Kraft Ltda.

RAPINI, A., J. FONTELLA PEREIRA \& D. J. GOYDER. (2011). Towards a stable generic circumscription in Oxypetalinae (Apocynaceae). Phytotaxa 26: 9-16.

https://doi.org/10.11646/phytotaxa.26.1.2

SCHULZ, A. G. (1937). Las asclepiadáceas del territorio del Chaco. Lilloa 1: 347-391.
STEARN, W. (2006). Latín Botánico, historia, gramática, sintaxis, terminología y vocabulario. Ed. Omega, Barcelona, $644 \mathrm{pp}$.

THIERS, B. [permanentemente actualizado, consulta 2018] Index Herbariorum: a global directory of public herbaria and associated staff. New York Botanical Garden's Virtual Herbarium, http://sweetgum.nybg.org/ih

VIEIRA, M. F. \& R. S. FONSECA. (2011). A casual cantharophily: the meeting between Astylus variegatus (Coleoptera: Myleridae) and Oxypetalum banksii (Apocynaceae: Asclepiadoideae). Journal of Pollination Ecology 5: 86-89. https://doi.org/10.26786/1920-7603(2011)14 
